\title{
LAS MAESTRAS "RUDECINDAS"
}

Grace Prada Ortiz

Hemos de tener presente que históricamente el primer derecho, por el cual las mujeres dieron fuertes luchas, fue el derecho a la educación. Ese derecho que nos permite en la actualidad ocupar lugares en las aulas escolares y universitarias, es el que ha abierto espacios para que las mujeres ejerzamos el magisterio nacional.

Mucho antes de obtener el derecho al voto, las mujeres lucharon en Europa y América por educarse. Las múltiples voces que defendían la participación, de las mujeres en la educación pronto encontraron detractores, saltaron por doquier argumentos oscurantistas que negaban la educación a las mujeres. Diversos y perversos fueron los argumentos esgrimidos para excluir a las mujeres del conocimiento y el saber. 
La ciencia y la biología se utilizaron como dispositivos de poder, entonces los científicos argumentaron, que el cerebro de las mujeres era más pequeño que el de los hombres y carecía del peso necesario para cumplir con lo que el estudio requería. Otros argüían, la imposibilidad de conciliar la maternidad con el estudio, se decía que, si una mujer estudiaba durante su período de gestación, el futuro niño o niña pagaría las consecuencias con malformaciones genéticas, que su intelecto se debilitaría porque las neuronas y la energía que la madre invertía en el estudio, restarían fuerza e inteligencia a la criatura. Argumentos como estos y otros todavía más tenebrosos, se esgrimieron para contener la inserción de las mujeres en la educación.

Dichosamente han existido las transgresoras, como Sor Juana Inés de la Cruz, que a sus tres años aprendió a leer en el México Colonial, transgresora al elegir la reclusión conventual como estrategia para dedicar su vida al estudio y al saber.

Transgresora fue Manuelita Escalante, la primera mujer del Cartago Colonial, que se dedicó al estudio y difusión de la historia, la filosofía y la poesía, en una de las ciudades más conservadoras de la Costa Rica Colonial.

Hoy podemos agradecer a las mujeres pioneras de antaño, abrirnos espacio para compartir conocimientos y participar en la educación, de manera más o menos equitativa con nuestros compañeros varones.

Es importante reconocer a hombres visionarios que consideraron importante la educación de las mujeres, uno de ellos es el Dr. José Ma. Castro Madriz, quien en 1867, pusa-la primera piedra para la construcción del edificio del Colegio Normal de Niñas. 
Es mi tesis que, cualquier estudio que intente historiar a las mujeres costarricenses como forjadoras del pensamiento costarricense, estaría incompleto sin el aporte de las mujeres del magisterio.

Las "maestras Rudecindas" constituyen uno de los principales soportes, sobre los que se ha edificado la cultura e identidad nacional, son ellas la otra mitad de la sociedad, que ha forjado el pensamiento y la nacionalidad costarricense.

Nuestros historiadores y literatos han sido muy generosos rescatando el quehacer de los hombres, letras y su aporte a la cultura nacional, han consignado de manera puntual y cuidadosa cada uno de sus legados al pensamiento y destacaron de manera especial el trabajo intelectual de la "Generación del Olimpo".

Sin embargo, no ocurre lo mismo con las mujeres forjadoras de pensamiento, poco sabemos de la labor de ellas y menos aún de las "maestras Rudecindas", casi nada se ha escrito, sobre la infatigable labor de las mujeres del magisterio.

El trabajo intelectual de aquellas mujeres tejedoras del pensamiento costarricense, es invisible, a lo sumo se resalta el trabajo de la enseñanza, como obra de abnegación y.sacrificio lo que obviamente es cierto.

Calificar la labor intelectual de las mujeres como "abnegada y sacrificada" lleva implícito un tratamiento ideológico y religioso que se identifica con el "marianismo".

De acuerdo con la ideología patriarcal intrínseca en el modelo marianista, el ejercicio del magisterio con sacrificio 
y abnegación, es natural y propio de las mujeres. Las mujeres en razón de su biología y siguiendo el modelo de la Virgen María, están predispuestas a sacrificarse por los demás.

Asumiendo el quehacer del magisterio de las mujeres con esa visión patriarcal, es imposible que el trabajo intelectual de las maestras se considere creación intelectual.

No precisa saber nuestra historia cómo nació el nombre de la "maestra Rudecinda", carecemos de suficientes datos sobre su existencia. Tampoco está del todo claro, si es un personaje producto de la ficción o de la realidad, ciertamente el límite entre ficción y realidad, nunca se sabe dónde inicia y dónde termina. Tampoco es tan importante para la investigadora precisar ese límite.

De lo que sí tengo certeza, es que el imaginario colectivo, es capaz de dar vida a personajes que se mezclan y confunden entre lo ficcional y lo real maravilloso.

Como la historia oral da vida y crea personajes la "maestra Rudecinda" encarna a todas las mujeres de nuestra historia, que dedicaron sus vidas a la noble tarea de la enseñanza, labor que durante mucho tiempo, careció de reconocimiento económico y que tuvo a la pobreza como inseparable compañera.

Siendo la pobreza sombra y compañera de las maestras, es necesario resaltar lo que al respecto contó Angela Acuña:

"Las pobres maestras de aquel entonces pasaban grandes aprietos económicos. Ninguna de ellas recibía sueldo por su trabajo. Dice el señor Mata Valle que no estaba en la 
conciencia de institutrices y familiares pagar esa labor. Las discípulas le llevaban todos los viernes un pequeño obsequio, al gusto y facultades económicas de cada madre de familia, llamado "el punto" y consistía por lo común, en puñados de maíz, frijoles, huevos, panecillos de cacao y otras menudencias de igual insignificancia.

La absoluta pobreza de las maestras se reflejaba en todo, en la casa, los muebles, el traje, las costumbres y aún en el propio carácter.

No es posible que el semblante exprese satisfacción cuando se arrastra la existencia entre privaciones y congojas. De todas las labores humanas, la de enseñar excede en importancia, en esfuerzos, en responsabilidades; se dirige al corazón, a la inteligencia y es base sobre la cual se asientan muchas actividades del porvenir" (Acuña, T. II, 1970: 182).

Angela Acuña, resume las precarias condiciones en que vivían las desprendidas maestras de finales del siglo XIX. Ella afirmó que el carácter de las maestras era pobre, apreciación que no comparto y en la que difiero.

Coraje y valentía era lo que sobraba a tan emprendedoras mujeres, ellas trabajaban en condiciones de extrema pobreza y absoluta inequidad con respecto al mismo trabajo, que sí era remunerado, cuando un hombre lo realizaba.

Nunca fueron las maestras pobres de carácter, se caracterizaron por ser aguerridas defensoras de la democracia, demostraron ser fieras luchadoras de la paz y la soberanía nacional, prodigaron por doquier sus enseñanzas sobre el verdadero sentido del patriotismo.

Las "maestras Rudecindas" emergen del imaginario colectivo y se encarnan en cada una de las mujeres que han 
dado sus mejores años y su intelecto, a la formación de mujeres y hombres de la sociedad costarricense.

Símbolo, mito y realidad son y serán las mujeres que han apostado su vida, a la labor de la educación de las generaciones de todos los tiempos.

La identidad cultural de la sociedad costarricense no puede concebirse sin el aporte de aquellas mujeres, la construcción de nuestra nacionalidad sería impensable sin el esmerado trabajo de queridas y recordadas maestras.

Es Angela Acuña, quien nos da luces para conocer a la "maestra Rudecinda". Ella escribió lo que el maestro Macabeo Vargas sabía de la "maestra Rudecinda":

"La Rudecinda diz que vivía en la Campana del Carmen, allí por donde los Chavarría, donde ahora son la bicicletería de Palma y la Embajada de los Estados Unidos" (en Acuña: T. 1: 181)

Se cuenta que la "maestra Rudecinda" nació en 1857 y que ejerció como maestra en una escuelita privada. Don Mauricio Soto Alfaro contaba que:

"Muy pequeño, todavía se mencionaba en ese tiempo a la Maestra Rudecinda, sin que lograra conocerla, para verificar su existencia; sin embargo, eso mismo da fundamento para suponer que tuvo personalidad real" (ibíd.).

Realmente no importa si la "maestra Rudecinda" se alojó en un cuerpo humano determinado, lo que importa, es que en ella toman vida muchas y venerables "maestras Rudecindas" de nuestro país. 
Ciertamente, hubiese sido interesante tener mayor información sobre su vida y obra, pero son muchas las mujeres costarricenses, que encarnan el quehacer intelectual de las maestras reales o imaginarias que han contribuido a forjar el pensamiento costarricense desde el ejercicio del magisterio.

Poco menos que un fantasma y mucho más que una transmisora de conocimientos, la maestra Rudecinda, es un vivo ejemplo de la mujer forjadora de pensamiento en el siglo XIX.

A la maestra Rudecinda, la acompañan una pléyade de mujeres dedicadas a la noble tarea de la enseñanza, ellas inundan la historia del magisterio nacional, sin embargo ese tesonero trabajo no ha sido registrado como parte esencial de la manera del ser y el pensar de las y los costarricenses.

Es necesario hacer un reconocimiento a esa labor que ha pasado desapercibida en nuestra historia, en el quehacer político y en el pensamiento nacional.

La tenacidad y beligerancia de las mujeres que han ejercido el magisterio activamente en Costa Rica, no se ha reconocido en su justa dimensión, posiblemente por considerarse una labor extensiva de los quehaceres domésticos, tal vez, por mezquindad e incapacidad para reconocer la labor de las mujeres y también porque es hasta ahora que las mujeres nos dedicamos a historiar a las mujeres.

Mujeres fuertes y combativas inundan nuestra historia, mujeres que no temieron a los regímenes dictatoriales, mujeres que se enfrentaron con valentía a toda forma de opresión. 
Maestras como Matilde Carranza, Lilia González, Carmen Lyra, Lilia Ramos, promovieron manifestaciones en 1919, se levantaron contra la tiranía de los Tinoco y alzaron sus voces para defender la democracia costarricense de los primeros años del siglo XX. Es importante recordar que en Costa Rica, se inicia la celebración del Día del Maestro en 1920 , así se empezó a rendir homenaje a quienes se destacaban en la labor de enseñar.

En el año de 1922, el honor de formar parte de la Galería de Maestros de la Escuela de Aplicación de Heredia, le correspondió a Ester Silva.

Luego de un proceso de selección en el que compitió con insignes maestros de la talla de Miguel Obregón, Porfirio Brenes, Juan Rudín, Roberto Brenes Mesén, Carlos Gagini y Omar Dengo. Ester Silva obtuvo 140 votos a su favor, por mayoría logró ocupar un lugar en la Galería de Maestros.

En esa ocasión, le correspondió disertar sobre la labor de Ester Silva a la maestra Marcelina de Loría, quien la recordó así:

"Para la época negra que eclipsó la historia de Costa Rica, su civismo fue antorcha que alumbro a nuestro país para sacarlo de las tinieblas del despotismo. Se levantó airosa para derrocar al tirano. Entonces fue ella, con el corazón hecho una tea encendida y con valor de soldado fuerte, la que abrió campo en medio de la horda salvaje que quería hundir a Costa Rica y en medio de amenazas, balas, insultos, dio el primer toque de clarín para alentar a sus compatriotas que ardían en deseos de liberar a su pueblo, pero que la timidez propia del pacífico costarricense no les permitía emprender tan magna tarea. Como soldado fuerte es el orgullo nacional" (RA, T. 5, N²10, 1922:132). 
Con tan elocuente discurso se destaca la valentía de una mujer que sin embargo, es fuerte y heroica en tanto se la compara con la labor de un viril soldado, es orgullo de la patria, porque asume una posición que solamente se esperaba de un hombre. Obviamente nadie esperaba que una maestra como Ester Silva tuviese el coraje y la valentía para enfrentar a los tiranos.

Para que las acciones patrióticas de Ester Silva tuviesen valor, debía ser comparada con un hombre.

Ester Silva, al igual que otras maestras costarricenses, no evadió su compromiso social y asumió la defensa de la patria como cualquier otro patricio nacional. Dignificar el trabajo intelectual y su labor patriótica es muy importante para la historia con rostro de mujer. En la Costa Rica de 1922 hacer público el reconocimiento de su labor docente y su patriotismo era novedoso.

Las "maestras Rudecindas", emergen del fondo de la historia nacional como las míticas guerreras amazonas, incansables luchadoras de la patria, ellas han participado directamente en la formación de mujeres y hombres libres y soberanos.

Heredamos de las "maestras Rudecindas" una patria libre, democrática y menos ignorante. Ellas no se limitaron a la enseñanza, participaron activamente en política y mantuvieron una posición ideológica clara, fueron honorables mujeres que se mantuvieron lejos de la corrupción tan familiar en la actualidad.

Las innumerables mujeres del magisterio nacional, entraron a la cultura, a la educación y al conocimiento, no 
por una puerta o ventana que estuviese abierta y disponible para ellas; entraron a la cultura por una pequeña hendija que lograron abrir, sosteniendo tremendo pulso, con una sociedad que no estaba preparada, ni dispuesta a darles espacio como constructoras de la nación.

Se dedicaron las mujeres del magisterio, a cultivar el intelecto de las niñas y los niños de nuestro país. He aquí su aporte como forjadoras del pensamiento costarricense, un pensamiento que fueron puliendo con los más ricos y nobles valores, la democracia, la solidaridad, el patriotismo, la equidad y la paz social.

Me he apropiado del nombre de las "maestras Rudencidas", lo pongo en plural, para reconocer y rendir homenaje, a todas aquellas mujeres del magisterio nacional que a través de nuestra historia, se han convertido en forjadoras de pensamiento costarricense.

Concluyo este ensayo recordando en las "maestras Rudecindas" a todas aquellas de cuyo nombre sí quiero acordarme.

\section{BIBLIOGRAFÍA}

Acuña Angela. La mujer costarricense a través de cuatro siglos. T . I. Imprenta Nacional, 1969.

Revista Repertorio Americano. Tomo 5 , № 10, 1922. Palabras de Doña Marcelina Loría, Maestra de la Escuela de Niñas "Julia Lang". 